DISTRIBUTION STATEMENT A. Approved for public release; distribution is unlimited.

\title{
Broadband Scattering from Sand and Sand/Mud Sediments with Extensive Environmental Characterization
}

\author{
Brian Todd Hefner \\ Applied Physics Laboratory, University of Washington \\ 1013 NE 40th Street \\ Seattle, WA 98105 USA \\ phone: (206) 616-7558 fax: (206) 543-6785 email: hefner@apl.washington.edu
}

Award Number: N00014-13-1-0040

\section{LONG-TERM GOALS}

To model the effects of volume heterogeneities, both discrete and continuous, in scattering from sand and mud sediments. A better understanding of the role of heterogeneities in seabed scattering could lead to improvements in sediment characterization using remote sensing techniques and a greater understanding of the mechanisms that affect mid-frequency reverberation.

\section{OBJECTIVES}

While previous work [1] focused on high-frequency scattering $(200-500 \mathrm{kHz})$ from the sediment, the goal of this work is to understand the transition from high- to mid-frequency scattering, by extended the frequency range of backscattering measurements down to $2 \mathrm{kHz}$. For the Sediment Acoustics Experiment in 1999 (SAX99), the focus was on sub-critical grazing angles for which mid-frequency scattering was shown to be due to roughness scattering [2]. Research in SAX04 shifted to scattering above the critical angle where volume heterogeneity was found to be the dominant scattering mechanism [3]. The source of this heterogeneity was believed to be mud inclusions in the sediment that were generated by the passage of Hurricane Ivan. This sediment was certainly different than the SAX99 sediment and hence failed to resolve the questions that the previous experiment had generated.

The passage of the hurricane provided an opportunity to examine a complicated sediment, one that can be encountered in many shallow water environments, particularly in estuaries and at the mouths of rivers. In these environments, volume scattering can become important at all angles however the models developed to handle these environments remain largely untested.

The goal of this research is to further develop and test models of volume scattering by utilizing the existing suite of instrumentation previously developed at APL-UW for the study of high-frequency acoustics. These models include perturbation models applied to scattering from the seafloor due to heterogeneities in the sediment properties and models developed by Dr. Ivakin [4] for scattering from inclusions in the sediment. For the experiments in this effort, scattering data was collected in the Gulf of Mexico for a sand sediment and in St. Andrew's Bay for a sand/mud sediment. Both of these sites provide the opportunity to collect data and test models in environments similar to those encountered in SAX99 and SAX04. This will allow us to address the questions raised by those experiments about the relative importance of volume and roughness scattering. 


\section{Report Documentation Page}

Form Approved

OMB No. 0704-0188

Public reporting burden for the collection of information is estimated to average 1 hour per response, including the time for reviewing instructions, searching existing data sources, gathering and maintaining the data needed, and completing and reviewing the collection of information. Send comments regarding this burden estimate or any other aspect of this collection of information,

including suggestions for reducing this burden, to Washington Headquarters Services, Directorate for Information Operations and Reports, 1215 Jefferson Davis Highway, Suite 1204, Arlington

VA 22202-4302. Respondents should be aware that notwithstanding any other provision of law, no person shall be subject to a penalty for failing to comply with a collection of information if it

does not display a currently valid OMB control number.

1. REPORT DATE

30 SEP 2014

4. TITLE AND SUBTITLE

Broadband Scattering from Sand and Sand/Mud Sediments with Extensive Environmental Characterization

6. $\operatorname{AUTHOR}(\mathrm{S})$

7. PERFORMING ORGANIZATION NAME(S) AND ADDRESS(ES)

University of Washington,Applied Physics Laboratory,1013 NE 40th Street,Seattle,WA,98105

9. SPONSORING/MONITORING AGENCY NAME(S) AND ADDRESS(ES)

3. DATES COVERED

00-00-2014 to 00-00-2014

5a. CONTRACT NUMBER

5b. GRANT NUMBER

5c. PROGRAM ELEMENT NUMBER

5d. PROJECT NUMBER

5e. TASK NUMBER

5f. WORK UNIT NUMBER

8. PERFORMING ORGANIZATION REPORT NUMBER

10. SPONSOR/MONITOR'S ACRONYM(S)

11. SPONSOR/MONITOR'S REPORT NUMBER(S)

12. DISTRIBUTION/AVAILABILITY STATEMENT

Approved for public release; distribution unlimited

13. SUPPLEMENTARY NOTES

14. ABSTRACT

15. SUBJECT TERMS

16. SECURITY CLASSIFICATION OF:

a. REPORT

unclassified b. ABSTRACT

unclassified c. THIS PAGE

unclassified
17. LIMITATION OF ABSTRACT

Same as

Report (SAR)
18. NUMBER 19a. NAME OF

OF PAGES RESPONSIBLE PERSON

6 


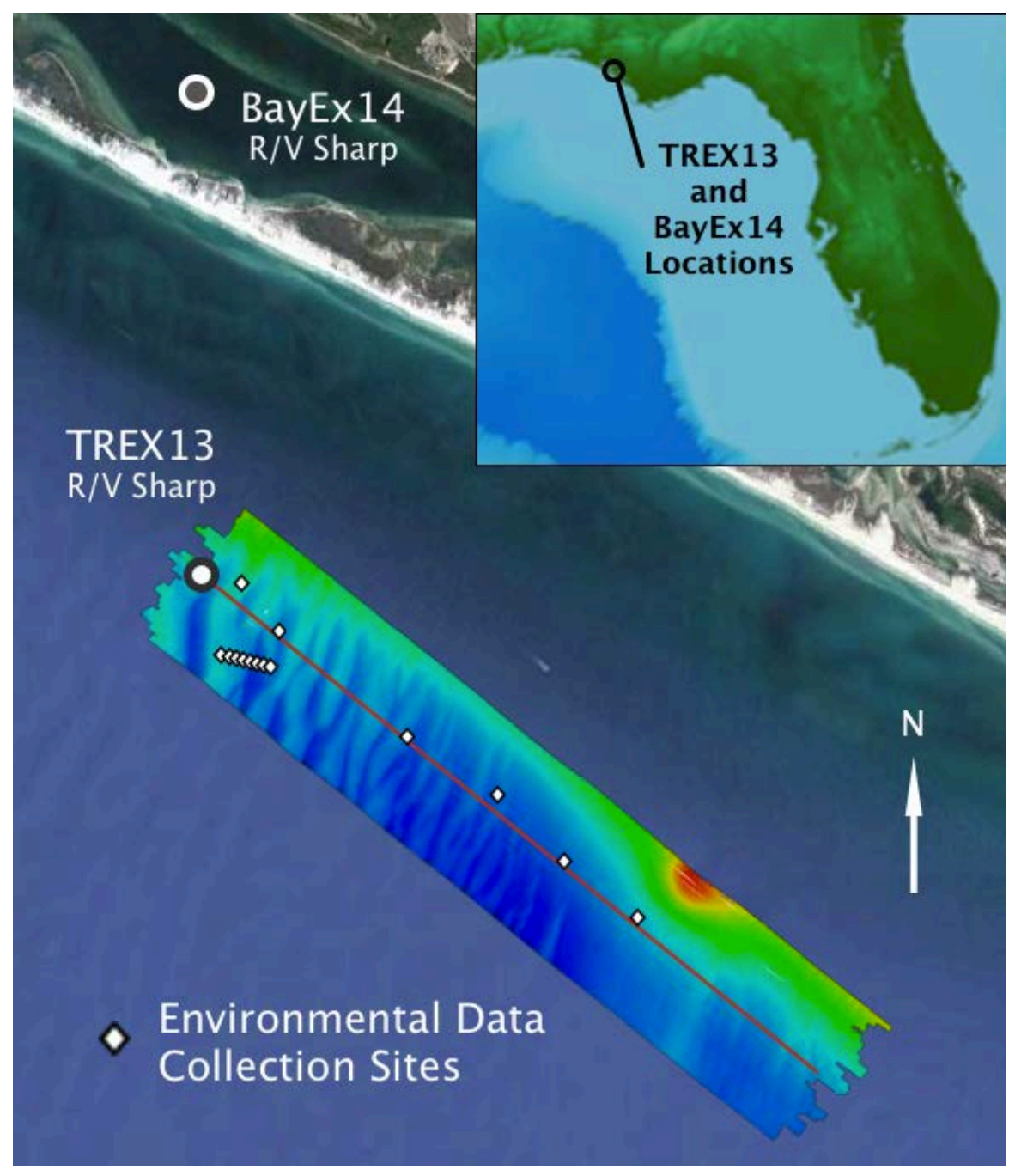

Figure 1: Locations of the TREX13 site and the BayEx14 site. The APL-UW SAS rail system was deployed from the $R / V$ Sharp while the ship was in a four-point moor at both locations.

Environmental characterization including seafloor roughness, heterogeneity, shell size distribution, sediment sound speed, and attenuation were collected at the locations of the rail system as well as the locations marked along the main reverberation track during TREX13.

In order to make the data/model comparisons, extensive environmental characterization was needed at both sites. This includes roughness measurements using the Laser-Line Scanner (LLS), conductivity probe measurements using the In-situ Measurement of Porosity (IMP2), sound speed and attenuation measurements, the collection of diver cores, and excavation of sediment volumes for shell size distributions. This environmental characterization was performed at both the target scattering site and along the main reverberation track of the Target and Reverberation Experiment in 2013 (TREX13). This data will be compiled and made available to the TREX13 participants and included in the environmental data set to be distributed as part of the TREX13 reverberation data set. Measurements in St. Andrew's Bay were conducted as part of the Bay Experiment in 2014 (BayEx14) 


\section{APPROACH}

To collect the acoustic scattering data, this work utilizes the APL-UW rail and tower that was deployed during both TREX13 and the BayEx14. The tower was originally developed for the Sediment

Acoustics Experiment 2004 (SAX04) and includes a high frequency array of sources and receivers as well as a piston source and receiver combination (EA33 and EA41) [3]. Since SAX04, the tower has been modified on several occasions, but the capability to operate with these legacy sonars remains intact. The high frequency array has since been reincorporated into the tower design and has been successfully deployed with the tower in both the NSWC-PC test pond and in the Gulf of Mexico. For TREX13, the piston source and receiver was reincorporated into the tower design for TREX13 and BayEx14. With these two systems backscatter data can be collected from $200-500 \mathrm{kHz}$ (source and receiver array) and from $20-150 \mathrm{kHz}$ (piston source and receiver) along the APL-UW rail and collocated with the SAS target field.

In preparation for TREX13, APL-UW developed the Bottom Sonar System (BSS). This system consists of an ITC-1007 source and a separate receiver in a small mount that can be deployed from a ship or boat. The BSS is suspended above the seafloor and transmits and receives pulses in the 2-20 $\mathrm{kHz}$ range. This system is designed to drift along a track collecting data at multiple locations. The frequency range of this system is such that it can measure both scattering from the seafloor and from subbottom layers. This system complements the measurements made by both the chirp sonar and the NSWC-PC BOSS at the TREX13 site. Between these three systems, backscatter can be measured from $2-500 \mathrm{kHz}$ capturing both mid and high-frequency scattering mechanisms.

This work was performed in close collaboration with the environmental measurements to be made at the experiment sites. The IMP2/LLS was deployed to collect bottom roughness and volume heterogeneity data in the target field and along the reverberation track, diver cores and sediment samples will be analyzed for shell size distribution, and an attenuation array was used to collect highfrequency sound speed and attenuation. These measurements are collocated with other environmental measurements including the sediment sound speed measurements by the SAMS and heterogeneity measurements made by the NSWC-PC BOSS.

\section{WORK COMPLETED}

The focus of this year's effort was on preparation and execution of BayEx14. This experiment took place in St. Andrew's Bay on the opposite side of shell island from the TREX13 location (Figure 1). The site sat in $8 \mathrm{~m}$ of water and the R/V Sharp was again deployed in a four-point moor at the site. The rail system was deployed during the experiment with the primary task of collecting synthetic aperture sonar data from targets deployed at the site as part of a separately funded ONR and Strategic Environmental Research and Development Program (SERDP) effort. During these efforts, a portion of the sediment in the target field was left undisturbed by divers and this area was used to collect backscatter data at the site. Efforts are underway to analyze this acoustic data.

In addition to the tower system, environmental data was also collected at the BayEx14 site. Throughout the site, the seafloor consisted of a layer of mud, roughly $10 \mathrm{~cm}$ thick, over a mixture of sand and silt (Right panel of Figure 2). The LLS was used to measure the roughness of the mud/water interface. Measurements were also made with the IMP2 conductivity probe to measure the roughness of both the mud/water and mud/sand interface and to characterize the heterogeneity in each medium. 
Diver cores were collected at site to measure the density and porosity of the mud and sand and to characterize the shell content in the sediment. Sound speed and attenuation were also measured in both the sand and the mud.
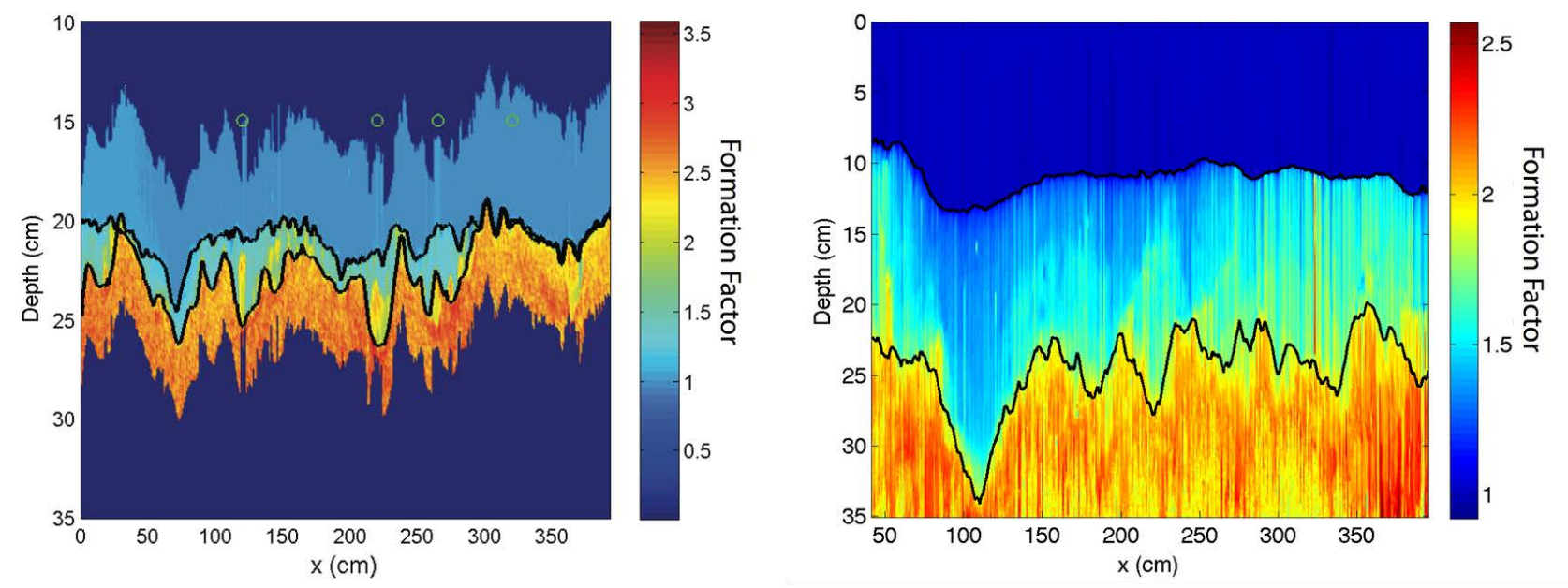

Figure 2: Conductivity probe measurements collected using the IMP2 during SAX04 (left panel) and BayEx14 (right panel). Displayed is the formation factor, $F$, which is the ratio of the resistivity measured by the probe to the resistivity measured in water. Both measurements show the overlying seawater $(F=1)$, a layer of mud $(F \sim 1.5)$, and a layer of sand $(F \sim 2-3)$. The mud/water and sand/mud interfaces are indicated with a black line. The areas with $F=0$ in the left panel are areas where data was not collected.

Analysis of the TREX13 data has also continued. During that experiment, while the acoustic data was successfully collected, modifications to the data acquisition system in the field made it necessary to recalibrate the system prior to data analysis. This calibration was performed this year and processing of the acoustic data is underway. The analysis of the environmental data collected during TREX13 has also continued during the past year. Dr. Dapeng Zhou, a visiting scientist from Guandong University of Technology, completed analysis of the diver cores and sediment samples collected at the TREX13 site along the main reverberation track (locations shown in Figure 1). This analysis included measurements of the density, porosity, and shell size distribution. These results are being integrated into the overall environmental description of the site and are being used to understand related data sets such as the sound speed and attenuation measurements made in collaboration with Laurent Guillon (Ecole navale/IRENav) and Xavier Demoulin (Maree).

\section{RESULTS}

One of the objectives in collecting data at the BayEx14 site was to increase our understanding of the acoustics of environments where there is a mud layer over a sand bottom. This type of environment was encountered during SAX04 as a consequence of Hurricane Ivan. The IMP2 was deployed during that experiment and was able to measure the roughness of both the mud/water and $\mathrm{mud} / \mathrm{sand}$ interfaces when a mud layer was present (Left panel of Figure 2). The roughness power spectra of these two interfaces (Figure 3) indicate that the sand interface was rougher at low wavenumbers than the mud interface and the areas under the mud where rougher than areas where there was no mud. At high wavenumbers the mud interface is rougher by several $\mathrm{dB}$ than the sand interface. This high- 
wavenumber roughness is likely due to bioturbation due to fish where the fish produce fine scale roughness on the mud and reduce the large scale roughness. Since the fish cannot reach the sand beneath the mud, the large scale roughness of the sand interface is preserved. This sheltering of the sand interface, and preservation of a rippled sand bottom, was believed to result in enhanced sound penetration into the mud-covered seafloor and reduced backscatter which could increase the signal-tonoise ratio for buried target detection.
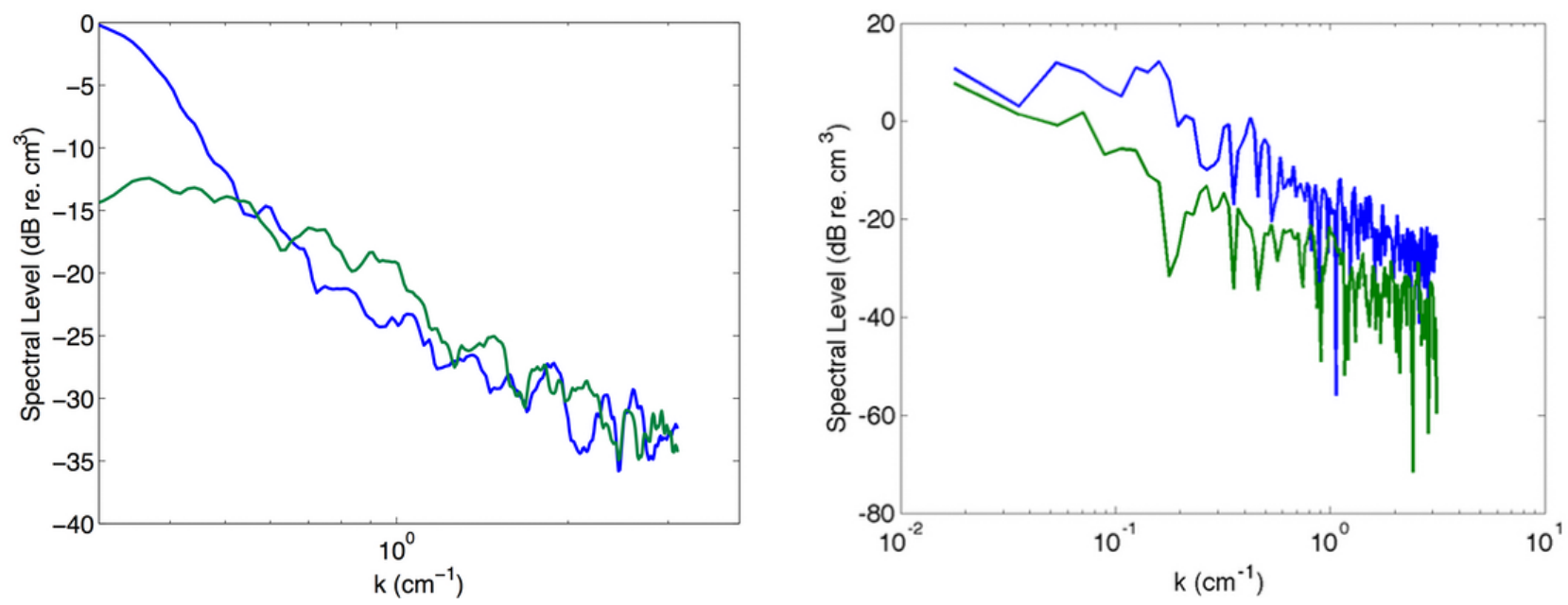

Figure 3: Roughness power spectrum for the mud/water (green) and sand/mud (blue) interfaces for the SAX04 (left panel) and BayEx14 (right panel) measurements in Figure 1.

A similar situation was observed at the BayEx14 site (Right panel of Figure 2). In the bay, the deposition of mud on the sand seafloor is likely driven by the transport of the material from rivers and flooding into the bay. This leads to a uniform mud layer throughout the site which persists for a long time; sand may very rarely be exposed. As with the SAX04 site, the sand interface is rougher at low wavenumbers than the mud interface (Right panel of Figure 3). This roughness may have been produced by strong currents or weather events and the mud again shelters the interface from the effects of fish. Unlike the SAX04 environment, the sand interface has significant small scale roughness and has a spectral level that is several $\mathrm{dB}$ higher than the mud interface. The cause of this fine scale roughness is unknown and it may lead to an increase in scattering from the seabed, reducing the signalto-noise ratio for target detection in this environment.

\section{IMPACT/APPLICATIONS}

A better understanding of the role of heterogeneities in scattering and its effect on forward propagation and reverberation in the ocean waveguide could lead to improvements in sediment characterization using remote sensing techniques. It will also contribute to our understanding of the effect of these heterogeneities on the statistics of target detection. 


\section{RELATED PROJECTS}

1. "Acoustic Color of mines and mine-like objects: Finite Element modeling (FEM), developing Automatic Target Recognition (ATR) strategies, and at-sea experimental validation." P.I. Kevin L. Williams funded by ONR.

2. "Mid-frequency reverberation measurements with full companion environmental support" P.I. Dajun Tang funded by ONR.

\section{REFERENCES}

1. B. T. Hefner, D. R. Jackson, A. N. Ivakin, and D. Tang, "High-frequency measurements of backscattering from heterogeneities and discrete scatterers in sand sediments," in the Proceedings of the European Conference on Underwater Acoustics 2010.

2. K. L. Williams, D. R. Jackson, E. I. Thorsos, D. Tang, and K. B. Briggs, “Acoustic backscattering experiments in a well characterized sand sediment: Data/model comparisons using sediment fluid and Biot models," IEEE J. Ocean. Eng., 27, 376-387 (2002).

3. K. L. Williams, D. Jackson, E. Thorsos, D. Tang, and S. Schock, "Acoustic Backscattering From a Sand and a Sand/Mud Environment: Experiments and Data/Model Comparisons," IEEE J. Ocean. Eng. 34, 388-398 (2009).

4. A. Ivakin, "Discrete scattering in marine sediments: A modeling approach and application to a shelly sand-mud environment," in the Proceeding of the European Conference on Underwater Acoustics 2010.

\section{PUBLICATIONS}

1. B. T. Hefner and D. R. Jackson, "Attenuation of sound in sand sediments due to porosity fluctuations,” J. Acoust. Soc. Am., 136, 583-595 (2014).

\section{HONORS/AWARDS/PRIZES}

2013 A. B. Wood Medal and Prize of the Institute of Acoustics awarded to Brian T. Hefner, Applied Physics Laboratory, University of Washington. 